\title{
12 Fashion, Fantasy, Power and Mystery Interpreting Shoes Through the Lens of Visual Culture
}

\section{Naomi Braithwaite}

\begin{abstract}
The high-heeled shoe has often been subjected to a myriad of cultural interpretations. Provoking connotations of power, eroticism, fragility and femininity, the high heel swings metaphorically between the objectification of female empowerment and a more negative association with the subordination of women. That shoes have an integral, fascinating and controversial place in culture is without doubt. Within a commercial sphere, shoe sales generate millions worldwide. Culturally their roles in stories such as Cinderella and The Wizard of Oz exemplify the transformative, magical and sometimes dark powers that they can hold. As fashion accessories high heels transform wearers aesthetically, physically and emotionally. It is as meaningful physical objects that high-heeled shoes have been most frequently scrutinised.

In response this chapter takes a different approach by exploring meaning through the lens of visual culture. By discussing how shoes are represented in fashion photography, in particular through the work of the French fashion photographer Guy Bourdin, the paper brings further understanding to Western culture's obsession with the mysterious and paradoxical nature of high heels. Bourdin was famed for his surrealist approach to fashion photography, focusing on theatrical composition and vivid colour use; he combined narrative storytelling with dark fantasy. Through the 1970s and into the 1980s Bourdin created campaigns for the renowned French shoe designer, Charles Jourdan, maker of exquisite high-heeled shoes. Drawing from semiotics, the author assumes the role of voyeur and observes the immersion of Jourdan's shoes within Bourdin's mysterious and sometimes sinister photographic world of storytelling. Bourdin's stylistic placement of shoes captures the imagination of viewers, drawing them into stories of femininity, mystery and eroticism. Key to the chapters argument is how the medium of fashion photography enables the cultural interrogation of the high heel, and, in so doing, reveals how images create and disseminate meaning.
\end{abstract}

\section{Keywords}

high heels - Guy Bourdin - Charles Jourdan - image - fashion - fantasy - femininity

\section{L1 1. Introduction}

Aomame pulled in her chin, kept her gaze fixed straight ahead, her back straight, and her pace steady. Her chestnut-colored Charles Jourdan heels clicked against the road's surface, and the skirts of her coat waved in the breeze. ${ }^{1}$

This extract comes from Murakami's 1Q84 as one of his key characters, Aomame begins her transition from an expressway in Tokyo, 1984, into the parallel universe of 1Q84. Her high-heeled Charles Jourdan shoes carry her on the journey that she takes between Murakami's two worlds, and through them we can almost feel her presence in these worlds. Aomame's passage to 1Q84 is down the expressway's emergency staircase and before descending she slips off her high heels and rolls up her skirt, liberating her body from the restrictions of these garments, and then, once 
descended, she steps back into her shoes, moving forward towards the unknown. ${ }^{2}$ Murakami's sensory description of Aomame's movement within and without the shoes prompts the reader to imagine the transformative power that the shoes have on her physicality. As she strides across the expressway they become metaphoric representations of femininity, but rather than the more stereotypical notions of feminine fragility there is empowerment.

Cultural interpretations of high heels swing between female empowerment and subordination. ${ }^{3}$ The shoe's transformative effect on the wearer's body, tightening calves and buttocks, projecting breasts forwards, has resulted in its associations with the erotic and fetishism. ${ }^{4}$ In the case of Aomame, Murakami's descriptions of her toned and lean physique lead the reader to imagine how the heel serves to exaggerate this disciplined feminine silhouette, combined with the clicking of the heel against the ground indicating a determined, empowered gait. The high heels present a more modern femininity, where the heel is a metaphor for confidence, empowerment and freedom. Murakami's rendering of the high-heeled shoe resonates with fairy tales, such as Cinderella or the Wizard of $\mathrm{Oz}$, where shoes have magical, transformative powers as they sit on the "thresholds between worlds or states of being. ${ }^{, 5}$ As one reads the opening passages of $1 Q 84$ there is a feeling of mystery and a sense of foreboding darkness to follow.

Through the descriptions of these shoes' relationship to the wearer's physique and demeanour, Murakami's extract sets the context of the paper which explores the cultural interpretations of the high heel. Theoretical meanings of the high heel are prolific and as they are culturally constructed they are open to shifting interpretations of femininity. ${ }^{6}$ That the high heel has been subjected to interrogation from a myriad of theoretical perspectives is without doubt and it is these which have led to its role in creating a particular image of the wearer's persona. While it is not the intention to challenge these different meanings, the paper intends to explore how the presentation of shoes in image fashion advertising may serve to create and disseminate further meaning to shoes.

Perusing the Vogue archives confirms the prominence that shoes have had from brand advertisements through to accessories in fashion spreads. ${ }^{7}$ During the 1970 s fashion advertising became more experimental with the creation of darker and sinister themes, evident in the pages of the French edition of Vogue and the work of French photographer Guy Bourdin. ${ }^{8}$ In addition to his work with Vogue, Bourdin created the advertising campaigns for the French shoe designer Charles Jourdan. Bourdin's images for Jourdan invited the observer into a world of dark, mysterious, often sinister stories, posing the question: what's happened here? Although the shoe is always there, it is the story being told around it that captures the imagination of the viewer.

While considering the cultural meanings of high heels, the chapter draws from particular Jourdan campaign images with the intention of questioning the role shoes play in fuelling the imagination and constructing stories in the viewer's minds: 
Bourdin's pictures mesmerized us with their views of a world of impossible glamour, impossible pleasure, impossible danger, a world of high adventure in which you never knew whether the boudoir door would open onto the rooftop, the desert, the palazzo, or the ditch. ${ }^{9}$

It is this sense of impossibility which sets in motion a desire to enter his photographic world and explore these images further.

\section{L1 2. Coming to Bourdin and Jourdan: A Reflective Approach}

The impact that Guy Bourdin (1928-1991) has had on the world of photography, fashion and visual culture is significant. During the 1960s and 1970s he was a photographer for the French edition of Vogue and designer Charles Jourdan. Bourdin was credited for disrupting the norms of fashion imagery. Moving away from traditional representations of beauty and the stylised representations of products, to create instead double page spreads filled with complex, compelling and often dark narratives. ${ }^{10}$ Biographical accounts of Bourdin tell how he came to photography in his twenties, being heavily inspired and later tutored by Man Ray. This accounts for the surrealist approach evident in his use of vivid colours and artistic experimentation with compositions. ${ }^{11}$

In 1954 Bourdin presented his work to Vogue where it caught the eye of Edmonde CharlesRoux, assistant to the editor-in-chief. Charles-Roux was recorded as saying that his images '... were men and women in the nude, showing only their back and bottom and sitting. The subject matter was extremely far from what could be of interest at Vogue, ${ }^{12}$ but the quality was 'exceptional.' 13

Chapeau-Choc (translated as 'Hat Shocker') was to be Bourdin's first commission for Vogue in 1955, where models posed in front of dead cows' heads and slabs of meat hanging from hooks, in the meat market of Paris's Les Halles. ${ }^{14}$ Despite a barrage of complaints, Bourdin continued to produce images for Vogue and by 1967, under the guidance of accessories editor Francine Crescent, every issue of Vogue had at least 20 pages of Bourdin's photographs. ${ }^{15}$

It was through Crescent that Bourdin was introduced to the French shoe designer Roland Jourdan, son of Charles Jourdan, in $1964 .{ }^{16}$ At the time Jourdan was looking for a different type of vitality in their advertising; something that went beyond the product. ${ }^{17}$ There was already a distinct shift in the nature of advertising imagery, evident in the work of other photographers like Helmut Newton, who was moving away from traditional product shots to a more explicit portrayal of narratives around fashion. ${ }^{18}$ The Jourdan brand was founded in 1919 by the shoemaker Charles. Jourdan's shoes were renowned for luxury, quality and innovative design, comparable with today's designers such as Christian Louboutin and Jimmy Choo.

In 1966 Bourdin shot his first campaign for Jourdan in New York. Their partnership was unique as Bourdin had control of artistic direction. For this campaign Bourdin requested giant shoes which

\footnotetext{
${ }^{9}$ L. Sante, 'Foreword', in S. Bourdin and G. Bourdin, Exhibit A, Jonathan Cape, London, 2001, pp. 4.

${ }^{10}$ R. Brooks, 'Sighs and Whispers', in C. Cotton and S. Verthime (eds.), Guy Bourdin, V\&A Publishing, London, 2003, pp. 126-133.

${ }^{11}$ A. Gingeras, Guy Bourdin, Phaidon Press Ltd., London, 2006.

${ }^{12}$ A. Haden-Guest, 'The Return of Guy Bourdin', The New Yorker, 7 November 1994 <https://www.newyorker.com/magazine/1994/11/07/thereturn-of-guy-bourdin > (Accessed 20 November 2017).

${ }^{13}$ Ibid.

${ }^{14}$ Gingeras, Guy Bourdin.

${ }^{15}$ Ibid.

${ }^{16}$ Haden-Guest, 'The Return of Guy Bourdin'.

${ }^{17}$ Y. Aubry, 'Guy Bourdin et Charles Jourdan', Zoom 83, 1981, pp. 78-85.

${ }^{18}$ C. Cotton, 'The Falsity of the Image', in C. Cotton and S. Verthime (eds.), Guy Bourdin, V\&A Publishing, London, 2003, pp. 142-149.
} 
Jourdan duly crafted. In one shot a model is seen running by the Brooklyn Bridge, while being chased by two gun toting New York cops. In another, the same shoe is pictured in a hotel corridor amidst lots of normal sized men's shoes. These images are almost fairytale-esque in their composition and resonate with the work of more contemporary images makers such as Tim Walker. Gérard Tavernas, Jourdan's head of Paris Office, recalled the resulting fervour from these images:"[i]t was if we were publishing not advertisements but a paperback novel or a comic strip...People were hungry to see what was next. ${ }^{, 19}$ What did come next were 15 years and over 30 campaigns for Jourdan which encompassed Bourdin's distinct and often sinister narratives. Fascination for these images still holds significance today, yet the focus for analysis is more usually centred on the images themselves with less attention given to the role that the Jourdan shoes may play in the narrative's significance.

In 1979 Bourdin, with a case full of Charles Jourdan sample shoes, a pair of female mannequin legs (cut off at the knees) and a Cadillac, came to the UK, taking a road trip, from Poole to Hadrian's Wall. Using the mannequin legs instead of a live model, he created the Walking Legs campaign: extraordinary images in ordinary settings - bus stops, gardens, by the sea front. It was seeing these images at the Guy Bourdin: Image Maker exhibition, Somerset House (London) in 2015, that initiated my intrigue in exploring further the work of Guy Bourdin and his photographic representation of shoes.

The motives for this paper are self-indulgent, having both a great passion for shoes and for Charles Jourdan. I have previously researched the meaning of shoes from the perspective of the designers who create them, through to the particular relationship women have to their high-heeled shoes. Before coming to academia, I worked for many years for a designer shoe brand that had been created by ex-Jourdan employees. I was fortunate enough to have worked with the designer who created the shoes featured in Bourdin's imagery and I spent years learning the Jourdan way of creating and selling shoes. This instigated a particular passion for the unique craftsmanship of Jourdan shoes, and I was to become an avid collector of vintage designs. My most treasured pair are black suede, high-heeled ankle boots with a distinctive metallic blue leather insignia on the outside edge, found in a vintage store called Resurrection in New York. My approach to shoes stems from material culture and explores how they objectify meaning in the lives of the women I have researched. More recently I have taken a self-reflective approach to material culture by cataloguing my own archive of shoes and recording how they each represent my biography. It was during this process that I visited the Bourdin exhibition and saw a photograph of my black ankle boots on a pair of mannequin legs, standing on the seafront, as if the absent body of the wearer was looking out to sea as a ship passes by. The role of fashion advertising has always been to manufacture desire for the product with a promise of an aspirational life. ${ }^{20}$ Yet here I was faced with an image of a product that was already part of my own biography and seeing it in the context of image brought to the fore the fact that these shoes had their own history and context which was contained within the realms of visual culture. It seemed important to explore then how images could become a medium for understanding what shoes mean both culturally and subjectively, and it is this that the paper will question. As a researcher of material culture, I was intrigued to see what examining shoes in images might bring to an understanding of heels as cultural signifiers and the role of advertising in transmitting meaning through culture.

\footnotetext{
${ }^{19}$ Haden-Guest, 'The Return of Guy Bourdin', p. 140.

${ }^{20}$ E. Shinkle, 'Introduction', in E. Shinkle (ed.), Fashion as Photograph: Viewing and Reviewing Images of Fashion, I.B. Tauris, London and New York, NY, 2012, pp. 1-13.
} 


\section{L1 3. From Product to Image: Interpreting High Heels Through Bourdin's Images}

Whether on or off, the body shoes express identity and gender. ${ }^{21}$ This is strikingly evident with the high heel, which is feminine, sexy, and eroticizes the body. ${ }^{22}$ When worn, the heel transforms the wearer physically, tilting the pelvis back, pronating the bottom and breasts, creating a wiggle or even totter ${ }^{23}$ In 'Techniques of the Body', the anthropologist Mauss noted the technical ability that was needed to walk in high heels, one that he found incomprehensible. ${ }^{24}$ The high heel has had an illustrious history from being worn foremost by men, to an emblem of femininity and elevated status, to associations with fetishism and more recently the choice of an empowered female. For feminists the high heel represents disempowerment and links to subordinate status. ${ }^{25}$ Although the heel is usually worn through choice and pleasure, its cultural interpretation fluctuates between empowerment and disempowerment. ${ }^{26}$ Stories of women being expected to wear high heels in the work place, for example, frequently appear in the media. ${ }^{27}$ It is in this contradictory context that a clear link can be seen between a cultural interpretation of the high heel and the presentation of femininity in advertising imagery which veers between that of being sexually degrading to a more modern approach encapsulating sexual empowerment. ${ }^{28}$ The high heel is vested with cultural meaning and different interpretations of femininity. While the paper does not intend to solve these contradictions, it does use them to explore how they may aid the interpretation of Bourdin's images.

In a visually saturated world, images are central in making meaning through culture. ${ }^{29}$ Meaning is encoded into images. Through their production and the context in which they are viewed, this meaning is then decoded both culturally and subjectively. Meaning, Berger stated, comes not just from what is known about the image and its message, but importantly the more mysterious, unknown qualities. ${ }^{30}$ Advertising imagery is explicit in its use of coded signs, and the fashion system depends on the spectacle of images to fuel consumer desire through codes that signify aspirational lifestyles. ${ }^{31}$ When it comes to a methodology for analysing images, Barthes' semiotic approach towards what the signifiers in the image are, in other words what it is of, and then what that signifies culturally, is the most usual point of reference. ${ }^{32}$ However, given the complexity of fashion images it may be more relevant to take a nuanced approach to the methodology. ${ }^{33}$ While the image analysis here has applied elements from semiotics to consider meaning, what has been

\footnotetext{
${ }^{21}$ A. Brydon, 'Sensible Shoes', in A. Brydon and S. Niessen (eds.), Consuming Fashion: Adorning the Transnational Body, Berg Publishers, Oxford and New York (NY), 1998, pp. 13-38.

${ }^{22}$ V. Steele and C. Hill, Shoe Obsession, Yale University Press, New Haven (CT) and London, 2012.

${ }^{23}$ Ibid.

${ }^{24}$ M. Mauss, 'Techniques of the Body', Economy and Society, vol. 2, no. 1,1973, pp. 70-89.

${ }^{25}$ S. Jeffreys, Beauty and Misogyny: Harmful Cultural Practices in the West, Routledge, London, 2005.

${ }^{26}$ Gamman, 'Self-Fashioning, Gender Display, and Sexy Girl Shoes'.

27 N. Khomami, 'London Receptionist Sent Home from PwC for Not Wearing High Heels', The Guardian, 11 May 2016 <https://www.theguardian.com/uk-news/2016/may/11/receptionist-sent-home-pwc-not-wearing-high-heels-pwc-nicola-thorp〉 (Accessed 18 August 2016).

${ }^{28}$ R. Gill, 'Empowerment/Sexism: Figuring Female Sexual Agency in Contemporary Advertising', Feminism and Psychology, vol. 18, no. 1, 2008, pp. 35-60.

${ }^{29}$ M. Sturken and L. Cartwright, Practices of Looking: An Introduction to Visual Culture, Oxford University Press, Oxford and New York (NY), 2001.

${ }^{30}$ J. Berger, Understanding a Photograph, Penguin Classics, London, 2013.

${ }^{31}$ Shinkle, 'Introduction'.

${ }^{32}$ R. Barthes, Image, Music and Text, William Collins, Sons \& Co, London, 1964.

${ }^{33}$ Shinkle, 'Introduction'.
} 
fundamental to their understanding is what Hall terms "negotiated reading, 34 implying some form of subjective analysis on the part of the researcher, which is informed by cultural connotations.

Many of the Jourdan images presented a distorted perspective of femininity, often containing some element of eroticism. An image from 1977 shows a maid with her maitresse de la maison fastening the ankle strap of her high-heeled strappy sandals, encapsulating the idea of both dominance and submission that surrounds the high heel. ${ }^{35}$ In other campaigns, Bourdin invites the viewer to be a voyeur of an unsettling, crime scene. The key image for analysis here is from Jourdan's 1975 campaign. Taking a semiotic approach to describe the image, a blue car sits behind a chalk outline of a female silhouette, stains on the street allude to blood and a pair of pink high heel wedges are abandoned on the pavement. It signifies that something bad has happened and that a woman, the fragile female perhaps, is the victim of an illicit crime. Yet there is not a trace of her bar the chalk line and her discarded pink shoes. Although the shoes are not central to the image, they are an important signifier of who she was. Taking a more nuanced and questioning approach perhaps the fragile female victim is not really what it is about, could the shoes belong to someone else, a femme fatale or a witness to the scene. In this context the more obvious meanings are immediately clouded by the mystery and incompleteness of the scenario presented. Bourdin's image triggers the imagination allowing minds to wander and create their own stories. The cultural meanings of high heels enable a reading of who the absent female might be.

Cotton argues that shoes rarely have a primary place in Bourdin's narratives. ${ }^{36}$ Yet the fact that they are not central perhaps makes them even more pertinent to the narrative. Bourdin was a proponent of Alfred Hitchcock's 'Macguffin technique' where inanimate objects, in this case shoes, serve as catalysts to the plot. ${ }^{37}$ What Bourdin achieves is the creation of a different image of fashion, with connotations of the erotic, fetishized femininity, dominance and submission, and somewhere within either on or off the body is a pair of high-heeled shoes. Although the shoes are not central to the image they have a role in the narrative that ultimately fulfilled the needs of advertising by selling product. ${ }^{38}$

Returning to Bourdin's Walking Legs campaign, what is striking here is the absent body, yet the mannequin legs are positioned in such a way that you can almost imagine the wearer's physicality. Bourdin has captured a sense of movement and the styles of the different shoes are imparting particular postures, where you can almost feel the resulting movement. Decoding images brings forth the ideas of journeys, resonating with Murakami's Aomame and fairy tales, where shoes guide movement between different places and senses of being. ${ }^{39}$ These images suggest the place that shoes have in imparting the wearer's physical presence in the world, dictating posture, movements and persona, which in these images seems to be that of an empowered but contemplative woman. Culture is undoubtedly significant in influencing the interpretation of images, however, we unavoidably decode subjectively, imparting our own ideals and emotions on what we read into the image. We see what we want to see and believe what we want, but culture does influence the choices that are made.

\section{L1 4. Conclusion}

\footnotetext{
${ }^{34}$ Sturken and Cartwright, Practices of Looking, pp. 57.

${ }^{35}$ J. Crump, 'Shoot to Thrill: Fetishism and Fashion Photography in the 1970s', in I. Vartanian (ed.), High Heels: Fashion, Femininity, Seduction,

Thames \& Hudson, London, 2011, pp. 36-57.

${ }^{36}$ Cotton, 'The Falsity of the Image'.

${ }^{37}$ Marriot, 'Inside the Surreal World of Guy Bourdin'.

${ }^{38} \mathrm{Ibid}$.

${ }^{39}$ Davidson, 'Shoes as Magical Objects'.
} 
By its very nature looking at images instigates an expectation of meaning. ${ }^{40}$ Perception as a situated bodily practice means that images are not only seen they are felt. ${ }^{41}$ It is this which triggers a more emotive and subjective interpretation. Shoe expert and academic, Valerie Steele, states that the meaning of the high-heeled shoe, 'is not inherent in the object itself. It's entirely something that's constructed by people in the society around it. ${ }^{42}$ This strikes a chord with how meaning is interpreted through images, where it stems from not just from what it portrays and the context in which it is seen but also the observer's cultural and subjective position. ${ }^{43}$

The volume of images that Bourdin created for Jourdan are immense, making it impossible to explore them all here, but what they each have is their own distinctive, mysterious, uncertain narrative which alludes to some reading of femininity. Whether on the live body, the disembodied mannequin legs or discarded in the corner of the image the high heel has a role to play in the images fuelling the narrative, stimulating the viewer's imagination and presenting a cultural perspective on femininity. The high heel is vested with conflicting cultural interpretations from subordination to empowerment and it is this which influences the subjective reading of the anonymous characters in Bourdin's narratives. Exploring the shoe's presentation in visual culture confirms its metaphoric role in the complexity of modern femininity and its ability to further stimulate culture's fascination with the high-heeled shoe.

\footnotetext{
${ }^{40}$ Berger, Understanding a Photograph.

${ }^{41}$ E. Shinkle, 'The Line Between the Wall and the Floor: Reality and Affect in Contemporary Fashion Photography', in E. Shinkle (ed.), Fashion as Photograph: Viewing and Reviewing Images of Fashion, I.B. Tauris, London and New York, NY, 2012, pp. 214-226.

${ }^{42}$ V. Steele, 'In Conversation', in I. Vartanian (ed.), High Heels: Fashion, Femininity, Seduction, Thames \& Hudson, London, 2011, pp. 58-104, pp. 58.

${ }^{43}$ Sturken and Cartwright, Practices of Looking.
} 


\section{Bibliography}

Aubry, Y., 'Guy Bourdin et Charles Jourdan'. Zoom 83, 1981, pp. 78-85.

Barthes, R., Image, Music and Text. William Collins, Sons \& Co, London, 1964.

Commented [FC1]: Clarify nature of the source

NM - Zoom magazine? I

Commented [BN02R1]: It is a magazine yes.

Berger, J., Understanding a Photograph. Penguin Classics, London, 2013.

Bourdin, S., and G. Bourdin, Exhibit A. Jonathan Cape, London, 2001.

Brooks, R., 'Sighs and Whispers', in C. Cotton and S. Verthime (eds.), Guy Bourdin. V\&A Publishing, London, 2003, pp. 126-133.

Brydon, A., 'Sensible Shoes', in A. Brydon and S. Niessen (eds.), Consuming Fashion: Adorning the Transnational Body. Berg Publishers, Oxford and New York (NY), 1998, pp. 13-38.

Cotton, C., 'The Falsity of the Image', in C. Cotton and S. Verthime (eds.), Guy Bourdin. V\&A Publishing, London, 2003, pp. 142-149.

Crump, J., 'Shoot to Thrill: Fetishism and Fashion Photography in the 1970s', in I. Vartanian (ed.), High Heels: Fashion, Femininity, Seduction. Thames \& Hudson, London, 2011, pp. 36-57.

Davidson, H., 'Shoes as Magical Objects', in H. Persson (ed.), Shoes: Pleasure and Pain. V\&A Publishing, London, 2015, pp. 24-35.

Gamman, L., 'Self-Fashioning, Gender Display, and Sexy Girl Shoes: What's at Stake - Female Fetishism or Narcissism?', in S. Benstock and S. Ferriss (eds.), Footnotes: On Shoes. Rutgers University Press, New Brunswick (NJ) and London, 2001, pp. 93-115.

Gill, R., 'Empowerment/Sexism: Figuring Female Sexual Agency in Contemporary Advertising', Feminism and Psychology, vol. 18, no. 1, 2008, pp. 35-60.

Gingeras, A., Guy Bourdin. Phaidon Press Ltd., London, 2006. 
Haden-Guest, A., 'The Return of Guy Bourdin', The New Yorker, 7 November 1994 <https://www.newyorker.com/magazine/1994/11/07/the-return-of-guy-bourdin > (Accessed 20 November 2017).

Jeffreys, S., Beauty and Misogyny: Harmful Cultural Practices in the West. Routledge, London, 2005.

Khomami, N., 'London Receptionist Sent Home from PwC for Not Wearing High Heels', The Guardian, 11 May 2016 <https://www.theguardian.com/uk-news/2016/may/11/receptionist-sent-home-pwc-not-wearinghigh-heels-pwc-nicola-thorp> (Accessed 18 August 2016).

Marriot, H., 'Inside the Surreal World of Guy Bourdin', The Guardian, 5 March 2015 <https://www.theguardian.com/fashion/2015/mar/05/surreal-world-guy-bourdin> (Accessed 10 August 2016).

Mauss, M., ‘Techniques of the Body', Economy and Society, vol. 2, no. 1,1973, pp. 70-89.

Murakami, H., 1Q84. Vintage Books, London, 2012.

Probert, C., Shoes in Vogue: Since 1910. Thames \& Hudson, London, 1981.

Sante, L., 'Foreword', in S. Bourdin, and G. Bourdin, Exhibit A. Jonathan Cape, London, 2001.

Semmelhack, E., 'The Allure of Power', in H. Persson (ed.), Shoes: Pleasure and Pain. V\&A Publishing, London, 2015, pp. 39-51.

Shinkle, E., 'Introduction', in E. Shinkle (ed.), Fashion as Photograph: Viewing and Reviewing Images of Fashion. I.B. Tauris, London and New York, NY, 2012, pp. 1-13.

Shinkle, E., 'The Line Between the Wall and the Floor: Reality and Affect in Contemporary Fashion Photography', in E. Shinkle (ed.), Fashion as Photograph: Viewing and Reviewing Images of Fashion. I.B. Tauris, London and New York, NY, 2012, pp. 214-226.

Steele, V., 'In Conversation', in I. Vartanian (ed.), High Heels: Fashion, Femininity, Seduction. Thames \& Hudson, London, 2011, pp. 58-104.

Steele, V., and C. Hill, Shoe Obsession. Yale University Press, New Haven (CT) and London, 2012. 
Steele, V., Fetish: Fashion, Sex and Power. Oxford University Press, Oxford and New York (NY), 1996.

Sturken, M., and L. Cartwright, Practices of Looking: An Introduction to Visual Culture. Oxford University Press, Oxford and New York (NY), 2001. 